\title{
Potencial do carvão ativado, filtro amarelo e interação fotoperíodo/temperatura na formação de raízes tuberosas de batata-doce in vitro
}

\author{
Potential of active charcoal, yellow filter and interation photoperiod/temperature on \\ the formation of tuber roots of sweet potato in vitro
}

\author{
Ricardo Monteiro Corrêa ${ }^{1}$ José Eduardo Brasil Pereira Pinto ${ }^{2}$ Suzan Kelly Vilela Bertolucci ${ }^{3}$ \\ Érika Soares Reis ${ }^{1}$ Ana Valéria de Souza ${ }^{4}$
}

RESUMO

Neste presente trabalho, avaliou-se o potencial do carvão ativado, filtro amarelo e a interação fotoperiodo/ temperatura na formação de estruturas semelhantes a raizes tuberosas de batata-doce (Ipomoea batatas L. Lam) em condições in vitro. $O$ experimento com carvão ativado foi conduzido em tubos de ensaio de $150 \mathrm{~mm} \times 25 \mathrm{~mm}$, contendo $10 \mathrm{ml}$ de meio de cultura por tubo. Nos experimentos com filtro amarelo e fotoperiodo/temperatura foram utilizados frascos contendo 15 e $30 \mathrm{ml}$, respectivamente de meio de cultura por frasco. $O$ meio de cultura utilizado em todos os tratamentos foi o MS. Nos 3 experimentos, avaliou-se o número de estruturas semelhantes a raizes tuberosas, peso seco de raizes e parte aérea. Em relação ao carvão ativado, notou-se que a sua associação com ácido naftaleno acético, benzilaminopurina e cinetina prejudicou a formação de estruturas semelhantes a raizes tuberosas além de proporcionar baixo peso seco de raízes e parte aérea. Em relação ao filtro amarelo, notou-se que sua presença com a associação de reguladores de crescimento (ácido nafatleno acético, benzilaminopurina e cinetina) proporcionou maior formação de estruturas semelhantes a raízes tuberosas, maior peso seco de raízes e parte aérea. Com relação à interação fotoperiodo e temperatura, os tratamentos que mantiveram a temperatura constante de $15^{\circ} \mathrm{C}$, submetidos a fotoperiodos de 8,10 e $12 \mathrm{~h}$ luz, mesmo na presença de ácido naftaleno acético e cinetina, reduziram a formação de estruturas semelhantes a raizes tuberosas, peso seco de raizes e parte aérea.

Palavras-chave: raiz tuberosa, reguladores de crescimento, carvão ativado, fotoperiodo, e filtro amarelo.

\begin{abstract}
In this present work the activated charcoal potential, yellow filter and photoperiod/temperature interaction in vitro on the formation of structures like tuber roots of sweet potato Ipomoea batatas L. Lam were evaluated. The experiment with activated charcoal was carried out in glass culture, each tube with $10 \mathrm{ml}$ of culture medium. The experiments with yellow filter and photoperiod/temperature were carried out in glass jars content each 15 and $30 \mathrm{ml}$ of medium of culture respectivy. The culture medium used in the treatments was the MS. In these three experiments carried out the number of structures like tuber roots dry matter of roots and aerial parts were evaluated. In relation to the activated charcoal, its presence associated with naphthalene acetic acid, benzylaminopurine and kinetin did not induce the formation of structures like tuber roots and reached proportioned low dry matter in both roots and aerial parts. In relation to the yellow filter, its presence associated with growth regulators (naphthalene acetic acid, benzylaminopurine and kinetin) proportioned larger formation of structures like tuber roots, high dry matter of roots and aerial part. The photoperiod $(8,10$ and 12 hours of light) associated with temperature $\left(15^{\circ} \mathrm{C}\right)$ proportioned low formation of structures like tuber roots, low dry matter of roots and aerial part.
\end{abstract}

Key words: tuber root, growth regulators, activated charcoal, photoperiod and yellow filter.

\section{INTRODUÇÃo}

A batata-doce (Ipomoea batatas (L.) Lam.) é uma dicotiledônea da família Convolvulaceae. Sua

\footnotetext{
${ }^{1}$ Acadêmicos do curso de Agronomia, Universidade Federal de Lavras (UFLA), Bolsista de Iniciação Científica, CNPq.

${ }^{2}$ Engenheiro Agrônomo, PhD., Professor, Departamento de Agricultura da UFLA, CP 37, 37.200-000, Lavras, MG. E-mail: jeduardo@ufla.br. Autor para correspondência.

${ }^{3}$ Farmacêutico, MSc., Professor, Departamento de Agricultura, UFLA.

${ }^{4}$ Engenheiro Agrônomo, Mestrando em Fitotecnia, UFLA.
} 
principal característica é ser um alimento altamente energético muito rico em carboidratos (superior a $30 \%$ em média em peso da matéria fresca) e boa fonte de vitaminas, principalmente B e C. Além disso, as cultivares de polpa amarela apresentam elevados teores de $\beta$-carotenos, substância precursora da vitamina A, de grande importância nutricional e industrial (FOLQUER, 1978).

Em relação à propagação da batata-doce, os métodos tradicionalmente utilizados são os vegetativos por meio das ramas e raízes tuberosas (FOLQUER, 1978). Porém, estes métodos de propagação apresentam sérios problemas, dentre os quais se destaca a dificuldade de conservação do material, disseminação de pragas e doenças, pequena capacidade multiplicativa do material disponível, desuniformidade nos plantios e baixa produtividade. Além disso, pode ocorrer degenerescência em decorrência do acúmulo de doenças, principalmente viróticas, no material de propagação (SILVA et al., 1991).

As raízes tuberosas de batata-doce poderiam ser produzidas in vitro, as quais seriam utilizadas na conservação de diferentes genótipos em bancos de germoplasma e intercâmbio deste material, tendo sido verificado serem menos vulneráveis aos fatores que afetam as plântulas in vitro, além de poderem ser, facilmente, transplantadas e estabelecidas in vivo (WANG \& HU, 1982). Desta forma, a produção de raízes tuberosas de batata-doce in vitro apresentase como uma técnica alternativa para otimizar sua conservação, além de possibilitar o estudo dos fatores que afetam fisiologicamente os processos de formações de tais raízes.

É sabido que um dos fatores físicos necessários para o crescimento e desenvolvimento de órgãos vegetativos subterrâneos é a ausência de luz. Diante disto, o carvão ativado tem sido utilizado em meios de cultura para estimular o enraizamento, devido à sua alta habilidade em excluir a luz do meio e também por diminuir a intoxicação das culturas pela presença de fenóis produzidos pelos próprios tecidos. A toxidez produzida por estas substâncias fenólicas inibem o enraizamento, como ocorre com a tamareira (TISSERAT, 1982). Além disto, o carvão tem sido utilizado para promover a morfogênese, particularmente a embriogênese, como relatado por FRIDBORG \& ERIKSSON (1975), os quais conseguiram restaurar a capacidade embriogênica em culturas velhas de cenoura.

A luz oriunda de lâmpadas fluorescentes (luz branca) pode induzir a produção de formaldeído e deficiência de ferro nas plantas de cultura de tecidos. O formaldeído é produzido pelo EDTA (etilenodiaminotetracético), quando este é oxidado pela redução fotoquímica do ferro, podendo ser acumulado em níveis inibidores. Além disso, o meio se torna deficiente em ferro porque o mesmo se torna desquelatado, vindo a precipitar. (HANGARTER \& STASINOPOULOS, 1991). O bloqueio da luz no intervalo de 290 a $450 \mathrm{~nm}$ com filtro amarelo pode promover mudanças fotoquímicas do meio, impedindo a produção de formaldeído e deficiência de ferro nas plantas in vitro (STASINOPOULOS \& HANGARTER, 1990 e HANGARTER \& STASINOPOULOS, 1991). Acredita-se que a redução no crescimento de calos de Lycopersicon esculentum L, Daucus carota L. e Arabidopsis thaliana L., causado pela luz branca não filtrada, pode ser mais atribuída às alterações fotoquímicas no meio de cultura que às funções fotosensoriais dos tecidos das plantas (HANGARTER \& STASINOPOULOS, 1991).

Outros fatores determinantes do crescimento e do desenvolvimento na maioria dos sistemas de cultura in vitro são a composição e a concentração de reguladores de crescimento no meio de cultivo. A presença de ácido jasmônico, benzil adenina, ácido naftaleno acético e benzilaminopurina provocaram a indução na formação de raízes tuberosas de plântulas de batata-doce (FIGUEIREDO, 1995). A aplicação de benzilaminopurina (50ppm) via foliar na tuberização de folhas enraizadas in vivo de I. batatas proporcionou maior produção em número e em peso da matéria seca das raízes tuberosas, quando comparadas com aquelas produzidas nos demais tratamentos, indicando efeito estimulador de crescimento sobre o processo de formação de raízes tuberosas (MC DAVID \& ALAMU, 1980). Ácido naftaleno acético isoladamente não tem influência alguma sobre o processo de formação de raízes tuberosas e benzilaminopurina favorece o maior dreno em direção ao sistema radicular (FIGUEIREDO, 1995).

O crescimento e desenvolvimento das plantas dependem da luminosidade para os processos fotossintéticos e de fotomorfogênese, nos quais podem estar envolvidos, isolada ou conjuntamente, os três seguintes parâmetros da luz: qualidade (comprimento de onda), quantidade (intensidade luminosa ou fluxo de fótons) e duração (fotoperíodo) (ECONOMU \& READ, 1987). Diferentes fotoperíodos (0, 8, 12, 16 e 24 horas de luz) não proporcionaram efeitos indutores na formação de raízes tuberosas in vitro da cultivar "Brazlândia Branca" de batata-doce (FIGUEIREDO, 1995).

O objetivo do presente trabalho foi avaliar a influência de carvão ativado, filtro amarelo e a associação entre fotoperíodo e temperatura na formação 
de raízes tuberosas de $\boldsymbol{I}$. batatas cv. "Brazlândia Branca", visando à produção de batata-semente de boa qualidade e isenta de patógenos .

\section{MATERIAL E MÉTODOS}

O trabalho foi desenvolvido no Laboratório de Cultura de Tecidos Vegetais, da Universidade Federal de Lavras (UFLA), Minas Gerais, no período de agosto de 2000 a julho de 2001.

O material vegetal foi estabelecido in vitro a partir de meristemas, que foram obtidos a partir de brotações de ramas de batata-doce cv. "Brazlândia Branca". Todos os experimentos foram realizados com a cultivar "Brazlândia Branca". Foram realizados três experimentos sendo que em todos os meios de cultura contendo sacarose a $3 \% \mathrm{p} / \mathrm{v}$ foram solidificados com ágar a $0,6 \% \mathrm{p} / \mathrm{v}$ e autoclavados a $121 \pm 1^{\circ} \mathrm{C}$. Com exceção ao experimento de fotoperíodo/temperatura que utilizou a temperatura de $15^{\circ} \mathrm{C}$, os demais foram mantidos em sala de crescimento sob temperatura constante de $25 \pm 1^{\circ} \mathrm{C}$, fotoperíodo de 16 horas, utilizando lâmpadas GE de $40 \mathrm{~W}$ do dia especial. As variáveis de respostas experimentais foram: número de estruturas semelhantes a raízes tuberosas; peso seco da parte aérea e peso seco de raízes.

\section{EXPERIMENTO I: Efeito do carvão ativado}

Os explantes [plântulas preestabelecidas in vitro através de multiplicação em meio MS (MURASHIGE \& SKOOG, 1962) com metade da concentração dos sais, com idade de 72 dias e altura média de 4 a $6 \mathrm{~cm}$ ] foram transferidos para o meio de indução, composto do meio MS sólido suplementado com diferentes concentrações de carvão ativado e combinações de reguladores de crescimento, a saber: carvão ativado a $1 \%+$ cinetina $\left(6 \mathrm{mg} \mathrm{L}^{-1}\right)+$ ácido naftaleno acético $\left(0,3 \mathrm{mg} \mathrm{L}^{-1}\right)$; carvão ativado a $0,5 \%+$ cinetina $\left(6 \mathrm{mg} \mathrm{L}^{-1}\right)+$ ácido naftaleno acético $\left(0,3 \mathrm{mg} \mathrm{L}^{-1}\right)$; carvão ativado a $1 \%$ + benzilaminopurina $\left(2 \mathrm{mg} \mathrm{L}^{-1}\right)+$ ácido naftaleno acético $\left(0,3 \mathrm{mg} \mathrm{L}^{-1}\right)$; carvão ativado a $0,5 \%+$ benzilaminopurina $\left(2 \mathrm{mg} \mathrm{L}^{-1}\right)+$ ácido naftaleno acético $\left(0,3 \mathrm{mg} \mathrm{L}^{-1}\right)$; carvão ativado a $0 \%+$ cinetina $\left(6 \mathrm{mg} \mathrm{L}^{-1}\right)+$ ácido naftaleno acético $\left(0,3 \mathrm{mg} \mathrm{L}^{-1}\right)$; carvão ativado a $0 \%+$ benzilaminopurina $\left(2 \mathrm{mg} \mathrm{L}^{-1}\right)+$ ácido naftaleno acético $\left(0,3 \mathrm{mg} \mathrm{L}^{-1}\right)$.

O delineamento experimental foi inteiramente casualizado com quatro repetições sendo, cada parcela constituída por quatro tubos de ensaio e uma planta por tubo. Os tubos utilizados foram de $150 \mathrm{~mm} \times 25 \mathrm{~mm}$ contendo $10 \mathrm{ml}$ de meio de cultura, vedando-os com tampa plástica e parafilme após a inoculação dos explantes. A avaliação do experimento foi feita ao final de 81 dias, quando iniciada a senescência, identificada pelo amarelecimento e queda das folhas.

\section{EXPERIMENTO II: Efeito do filtro amarelo}

Os explantes (plântulas preestabelecidas in vitro através de multiplicação em meio MS com metade da concentração dos sais, com idade de 45 dias e altura média de $4 \mathrm{a} 6 \mathrm{~cm}$ ) foram transferidos para o meio de indução constituído do meio MS sólido suplementado com diferentes combinações de reguladores de crescimento, na ausência e presença de filtro amarelo de $3 \mathrm{~mm}$ de espessura, a saber: ausência de filtro amarelo + benzilaminopurina $\left(0 \mathrm{mg} \mathrm{L}^{-1}\right)+$ ácido naftaleno acético $\left(0 \mathrm{mg} \mathrm{L}^{-1}\right)$; filtro amarelo + benzilaminopurina $\left(2 \mathrm{mg} \mathrm{L}^{-1}\right)$ + ácido naftaleno acético $\left(4 \mathrm{mg} \mathrm{L}^{-1}\right)$; filtro amarelo + benzilaminopurina $\left(2 \mathrm{mg} \mathrm{L}^{-1}\right)+$ ácido naftaleno acético $\left(0,3 \mathrm{mg} \mathrm{L}^{-1}\right)$; filtro amarelo + cinetina $\left(6 \mathrm{mg} \mathrm{L}^{-1}\right)+$ ácido naftaleno acético $\left(0,3 \mathrm{mg} \mathrm{L}^{-1}\right)$.

O filtro amarelo foi colocado sobre os frascos, sendo as laterais e a base dos frascos, envolvidas com isopor para impedir a entrada de luz branca. O delineamento experimental utilizado foi o inteiramente casualizado com três repetições, sendo cada parcela constituída por cinco frascos e uma planta por frasco. Os frascos utilizados foram de $300 \mathrm{ml}$ contendo $15 \mathrm{ml}$ de meio de cultura e vedados com tampa plástica e parafilme após inoculação dos explantes. A avaliação do experimento foi feita ao final de 82 dias, previamente a senescência das plântulas.

\section{EXPERIMENTO III: Efeito do fotoperíodo e temperatura}

As plântulas preestabelecidas in vitro em meio MS com metade da concentração dos sais, com idade de 54 dias e altura média de 4 a $6 \mathrm{~cm}$, foram transferidas para frascos com capacidade de $300 \mathrm{ml}$ contendo $30 \mathrm{ml}$ de meio de indução, os quais foram vedados com tampa plástica e parafilme. $\mathrm{O}$ meio de indução utilizado foi o MS sólido suplementado com diferentes combinações de reguladores de crescimento sendo: $8 \mathrm{~h}$ claro $+16 \mathrm{~h}$ escuro + cinetina $\left(6 \mathrm{mg} \mathrm{L}^{-1}\right)+$ ácido naftaleno acético $\left(0,3 \mathrm{mg} \mathrm{L}^{-1}\right)$ à $15^{\circ} \mathrm{C} ; 16 \mathrm{~h}$ claro + 8 h escuro + cinetina $\left(6 \mathrm{mg} \mathrm{L}^{-1}\right)+$ ácido naftaleno acético $\left(0,3 \mathrm{mg} \mathrm{L}^{-1}\right)$ à $25^{\circ} \mathrm{C} ; 12 \mathrm{~h}$ claro $+12 \mathrm{~h}$ escuro + cinetina $\left(6 \mathrm{mg} \mathrm{L}^{-1}\right)+$ ácido naftaleno acético $\left(0,3 \mathrm{mg} \mathrm{L}^{-1}\right)$ à $15^{\circ} \mathrm{C}$; $10 \mathrm{~h}$ claro $+14 \mathrm{~h}$ escuro + cinetina $\left(6 \mathrm{mg} \mathrm{L}^{-1}\right)+$ ácido naftaleno acético $\left(0,3 \mathrm{mg} \mathrm{L}^{-1}\right)$ à $15^{\circ} \mathrm{C}$. Os tratamentos que utilizaram a temperatura de $15^{\circ} \mathrm{C}$ foram mantidos em câmara de crescimento com temperatura controlada (mod. $347 \mathrm{FG}$ ) e os de temperatura de $25^{\circ} \mathrm{C}$ mantidos em sala de crescimento. $O$ delineamento experimental foi o inteiramente casualizado com cinco repetições onde cada parcela continha quatro frascos com uma planta 
por frasco. A avaliação do experimento foi feita ao final de 82 dias, quando as plântulas começavam a entrar em senescência. Os dados dos três experimentos foram avaliados estatisticamente, utililizando-se o teste Scott \& Knott (SCOTT \& KNOTT, 1974) do software SISVAR (Lavras-MG, 1998) adotando-se 5\% de probabilidade de erro.

\section{RESULTADOS E DISCUSSÃO}

\section{Número médio de estruturas semelhantes a raízes tuberosas}

As estruturas obtidas nos três experimentos apresentaram-se sob variadas formas como cilíndricas, ovais e alongadas de tamanho variando entre 1 e $5 \mathrm{~mm}$ de comprimento e diâmetro de aproximadamente $1 \mathrm{~mm}$. Verificou-se que a presença de carvão ativado afetou negativamente a produção de estruturas semelhantes a raízes tuberosas, mesmo na presença de reguladores de crescimento. Por outro lado, a ausência deste fator e utilização da mesma concentração e interação auxina/ citocinina proporcionaram a formação destas estruturas como se pode observar na figura 1 . A combinação da auxina, ácido naftaleno acético, com a citocinina, benzilaminopurina, é importante para indução do processo de formação de estruturas semelhantes a raízes tuberosas in vitro em $\boldsymbol{I}$. batatas de acordo com FIGUEIREDO (1995). Porém, neste experimento, o carvão ativado inibiu a formação de estruturas semelhantes a raízes tuberosas, provavelmente devido à sua capacidade de adsorção impedindo a ação do acido naftaleno acético e das citocininas benzilaminopurina e cinetina, essenciais para a indução da formação de raízes tuberosas. Observou-se que, aqueles tratamentos nos quais o carvão ativado estava presente, não diferenciaram pois não apresentaram nenhuma raiz tuberosa. $\mathrm{O}$ mesmo aconteceu na ausência de carvão ativado e, embora a combinação de reguladores de crescimento tenha sido mantida, estes apresentaram, aproximadamente, em média cinco estruturas semelhantes a raízes tuberosas por explante (Figura 1).

O uso de filtro amarelo proporcionou a formação de estruturas semelhantes a raízes tuberosas quando se utilizou menor concentração de auxina (ANA - 0,3mg $\mathrm{L}^{-1}$ ) combinada com as citocininas (benzilaminopurina $-2 \mathrm{mg} \mathrm{L}^{-1}$ e cinetina $-6 \mathrm{mg} \mathrm{L}^{-1}$ ). Porém, quando a concentração de ácido naftaleno acético foi de $4 \mathrm{mg} \mathrm{L}^{-1}$ houve inibição na formação destas estruturas, mesmo na combinação com a citocinina (benzilaminopurina $-2 \mathrm{mg} \mathrm{L}^{-1}$ ). $\mathrm{Na}$ ausência de filtro amarelo e reguladores de crescimento, não houve formação de estruturas semelhantes a raízes tuberosas. Os resultados podem ser observados na figura 1. O filtro amarelo pode ser o mais indicado para um estudo na área de enraizamento, por ter induzido um aspecto tuberoso em mandioca (Manihot esculenta Crantz) (SATO, 1999).

Nos experimentos de fotoperíodo/ temperatura trabalhou-se com um tratamento diferenciado [ $16 \mathrm{~h}$ claro / $8 \mathrm{~h}$ escuro + cinetina $\left(6 \mathrm{mg} \mathrm{L}^{-1}\right)$ + ácido naftaleno acético $\left(0,3 \mathrm{mg} \mathrm{L}^{-1}\right)$ a $\left.25^{\circ} \mathrm{C}\right]$ procurando otimizar os resultados encontrados por FIGUEIREDO (1995) que utilizou o mesmo tratamento, porém sem reguladores de crescimento. Nos resultados apresentados por FIGUEIREDO (1995), houve uma boa produção de raízes, no entanto, não houve a formação de estruturas semelhantes a raízes tuberosas no meio indutor utilizado.

Isso mostra a importância da interação auxina/citocinina para a formação destas estruturas, como se observou no presente trabalho, no qual a exposição das plântulas em 16 horas de luz e temperatura de $25^{\circ} \mathrm{C}$ combinado com ácido naftaleno acético e cinetina proporcionaram a formação destas estruturas.

Diferentes fotoperíodos $(0,8,12,16$ e 24 horas de luz) associado à temperatura de $25^{\circ} \mathrm{C}$ não proporcionaram a formação de estruturas semelhantes a raízes tuberosas no trabalho desenvolvido por FIGUEIREDO (1995). Resultados semelhantes foram obtidos neste trabalho, quando a temperatura de $15^{\circ} \mathrm{C}$ e diferenciados tratamentos de fotoperíodo foram utilizados. Notou-se que a formação de estruturas semelhantes a raízes tuberosas foi prejudicada, proporcionando queimaduras nas plântulas e, com isto, diminuindo o acúmulo de reservas nas raízes. Em contrapartida, no tratamento que adotou a temperatura constante de $25^{\circ} \mathrm{C}$, sob 16 horas de luz acrescidos da combinação auxina (ácido naftaleno acético $-0,3 \mathrm{mg} \mathrm{L}^{-1}$ ) e citocinina (cinetina $-6 \mathrm{mg} \mathrm{L}^{-1}$ ), o número destas estruturas foi consideravelmente maior.

As condições necessárias para a formação de raízes tuberosas de batata-doce no campo são fotoperíodo curto e baixa luminosidade e temperatura (FOLQUER, 1978). No entanto, nestas mesmas condições in vitro, ou seja, fotoperíodo de 8,10 e 12 horas de luz e temperatura de $15^{\circ} \mathrm{C}$ associado a ácido naftaleno acético $\left(0,3 \mathrm{mg} \mathrm{L}^{-1}\right)$ e cinetina $\left(6 \mathrm{mg} \mathrm{L}^{-1}\right)$, a formação de estruturas semelhantes a raízes tuberosas foi estatisticamente menor, mesmo na presença indispensável da combinação de auxina e citocinina. Já em relação ao tratamento com maior fotoperíodo (16 horas de luz) e maior temperatura $\left(25^{\circ} \mathrm{C}\right)$, a formação destas estruturas foram significativamente maior (Figura 1). Conforme, já mencionado, trabalhos 
A

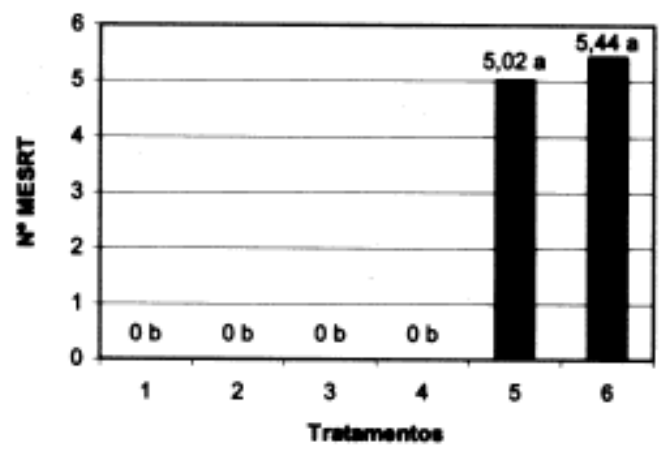

$\mathbf{B}$

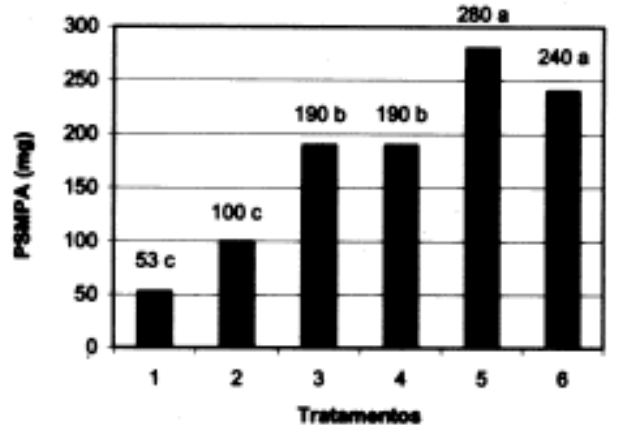

C

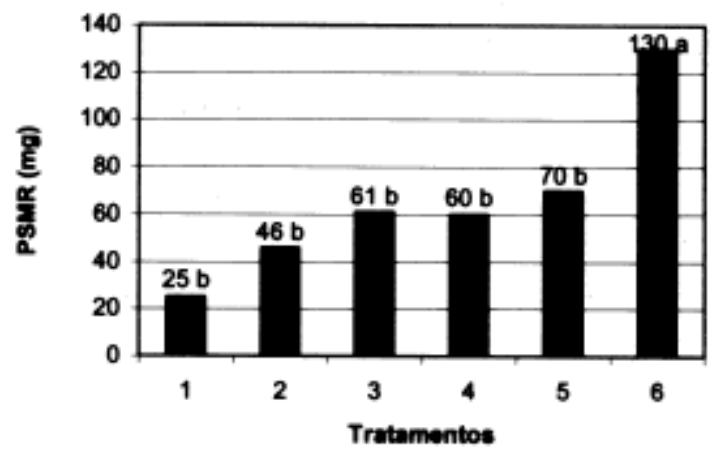

Figura 1 - Relação entre o número médio de estruturas semelhantes a raízes tuberosas ( $\left.\mathrm{N}^{\circ} \mathrm{MESRT}\right)$ - (A), peso seco médio da parte aérea (PSMPA) - (B) e o peso seco médio de raízes (PSMR) - (C) e os tratamentos: 1) Carvão ativado (CA)- (1\%) + ácido naftaleno acético (ANA)- $\left(0,3 \mathrm{mg} \mathrm{L}^{-1}\right)+$ cinetina $\left.(\mathrm{CIN})-\left(6 \mathrm{mg} \mathrm{L}^{-1}\right) ; 2\right) \mathrm{CA}(1 \%)+\mathrm{ANA}\left(0,3 \mathrm{mg} \mathrm{L}^{-1}\right)+$ benzilaminopurina (BAP)- $\left(2 \mathrm{mg} \mathrm{L}^{-1}\right)$; 3) $\mathrm{CA}(1 \%)+\mathrm{ANA}\left(0,3 \mathrm{mg} \mathrm{L}^{-1}\right)+$ benzilaminopurina (BAP)- $\left.\left.\left(2 \mathrm{mg} \mathrm{L}^{-1}\right) ; 4\right) \mathrm{CA}(0,5 \%)+\mathrm{ANA}\left(0,3 \mathrm{mg} \mathrm{L}^{-1}\right)+\mathrm{BAP}\left(2 \mathrm{mg} \mathrm{L}^{-1}\right) ; 5\right)$ Ausência de CA + ANA $\left.\left(0,3 \mathrm{mg} \mathrm{L}^{-1}\right)+\mathrm{CIN}\left(6 \mathrm{mg} \mathrm{L}^{-1}\right) ; 6\right)$ Ausência de CA + ANA $\left(0,3 \mathrm{mg} \mathrm{L}^{-1}\right)+$ BAP $\left(2 \mathrm{mg} \mathrm{L}^{-1}\right)$. Os valores não seguidos de mesma letra diferem entre si, pelo teste de Scott \& Knott em nível de 5\% de probabilidade de erro.

realizados por FIGUEIREDO (1995) reportam que diferentes fotoperíodos $(0,8,12$, e $24 \mathrm{~h}$ luz) não influenciaram a formação de raízes tuberosas em $\boldsymbol{I}$. batatas, porém no presente trabalho o fotoperíodo foi influenciado pelas condições de temperatura.

\section{Matéria seca da parte aérea (PSMPA):}

A presença de carvão ativado tanto nas concentrações de 0,5 e $1 \%$ inibiram o desenvolvimento da parte aérea de plântulas de batata-doce, mesmo com a presença indispensável de fitoreguladores. No entanto, a presença de ácido naftaleno acético $\left(0,3 \mathrm{mg} \mathrm{L}^{-1}\right)$ e benzilaminopurina $\left(2 \mathrm{mg} \mathrm{L}^{-1}\right)$ com 1 e $0,5 \%$ de carvão ativado respectivamente, se mostraram mais eficientes que a utilização de ácido naftaleno acético $\left(0,3 \mathrm{mg} \mathrm{L}^{-1}\right) \mathrm{e}$ cinetina $\left(6 \mathrm{mg} \mathrm{L}^{-1}\right)$ interagido com 1 e $0,5 \%$ de carvão ativado respectivamente. A ausência de carvão ativado juntamente com a interação ácido naftaleno acético $\left(0,3 \mathrm{mg} \mathrm{L}^{-1}\right)$ e benzilaminopurina $\left(2 \mathrm{mg} \mathrm{L}^{-1}\right)$ não se diferenciou da ausência de carvão ativado associado a ácido naftaleno acético $\left(0,3 \mathrm{mg} \mathrm{L}^{-1}\right)$ e cinetina $\left(6 \mathrm{mg} \mathrm{L}^{-1}\right)$. O carvão ativado não é um regulador de crescimento, mas modifica a composição do meio e, por isso, em algumas circunstâncias, melhora ou regula o crescimento da planta in vitro. Porém, o uso de carvão ativado pode diminuir a disponibilidade de reguladores de crescimento, tais como citocininas e ácido abscísico, como também de algumas auxinas (PASQUAL et al., 1997). A presença de carvão ativado em plântulas de mandioca (M. escculenta) in vitro acarretou redução no crescimento, sugerindo uma competição do carvão ativado com os sais do meio de cultura, não deixando os sais disponíveis para serem absorvidos pelas raízes das plântulas (ROCA et al., 1984).

No experimento com filtro amarelo, observou-se que, na ausência deste fator e de reguladores de crescimento, houve redução no peso seco da parte aérea em relação aos demais tratamentos 
(dois, três e quatro) que utilizaram filtro amarelo e as interações auxinas e citocininas. As interações ácido naftaleno acético $\left(4 \mathrm{mg} \mathrm{L}^{-1}\right)$ com benzilaminopurina (2 $\left.\mathrm{mg} \mathrm{L}^{-1}\right)$, ácido naftaleno acético $\left(0,3 \mathrm{mg} \mathrm{L}^{-1}\right)$ com benzilaminopurina $\left(2 \mathrm{mg} \mathrm{L}^{-1}\right)$ e ácido naftaleno acético $\left(0,3 \mathrm{mg} \mathrm{L}^{-1}\right)$ com cinetina $\left(6 \mathrm{mg} \mathrm{L}^{-1}\right)$ nos tratamentos dois, três e quatro respectivamente, não se diferenciaram entre si estatisticamente (Figura 2). Plântulas de mandioca (Manihot esculenta), sob efeito de filtro de luz de diversas cores, não mostraram diferença significativa no comprimento da parte aérea ao se utilizar os filtros de cores amarelo, azul e vermelho (SATO, 1999).

Observou-se que fotoperíodos de 8,10 e 12 horas de luz, associados à temperatura de $15^{\circ} \mathrm{C}$, proporcionaram maior redução na matéria seca da parte aérea em relação ao fotoperíodo de 16 horas de luz associado à temperatura de $25^{\circ} \mathrm{C}$ (Figura 2). FIGUEIREDO (1995) também constatou a influência do fotoperíodo no desenvolvimento da parte aérea de $\boldsymbol{I}$. batatas in vitro, e relatou o fotoperíodo de $16 \mathrm{~h}$ associado com a temperatura de $25^{\circ} \mathrm{C}$ como o melhor.

\section{Peso seco médio de raiz (PSMR):}

Observou-se que a presença de carvão ativado (0,5 e 1\%) associado a concentrações de auxina (ácido naftaleno acético) e citocininas (benzilaminopurina e cinetina) nos tratamentos um, dois, três e quatro, e ausência de carvão ativado interagido com ácido naftaleno acético $\left(0,3 \mathrm{mg} \mathrm{L}^{-1}\right)$ e cinetina $\left(6 \mathrm{mg} \mathrm{L}^{-1}\right)$, diminuíram como em outras variáveis de respostas já analisadas, o peso seco de raízes. Não houve diferença significativa no teor de matéria seca de raízes ao utilizar carvão ativado $(0,5$ e $1 \%)$ com ácido naftaleno acético $\left(0,3 \mathrm{mg} \mathrm{L}^{-1}\right)$ e cinetina $\left(6 \mathrm{mg} \mathrm{L}^{-1}\right)$; carvão ativado $(0,5$ e $1 \%)$ com ácido naftaleno acético $\left(0,3 \mathrm{mg} \mathrm{L}^{-1}\right)$ e benzilaminopurina $\left(4 \mathrm{mg} \mathrm{L}^{-1}\right)$; ausência de carvão ativado com ácido naftaleno acético $\left(0,3 \mathrm{mg} \mathrm{L}^{-1}\right) \mathrm{e}$

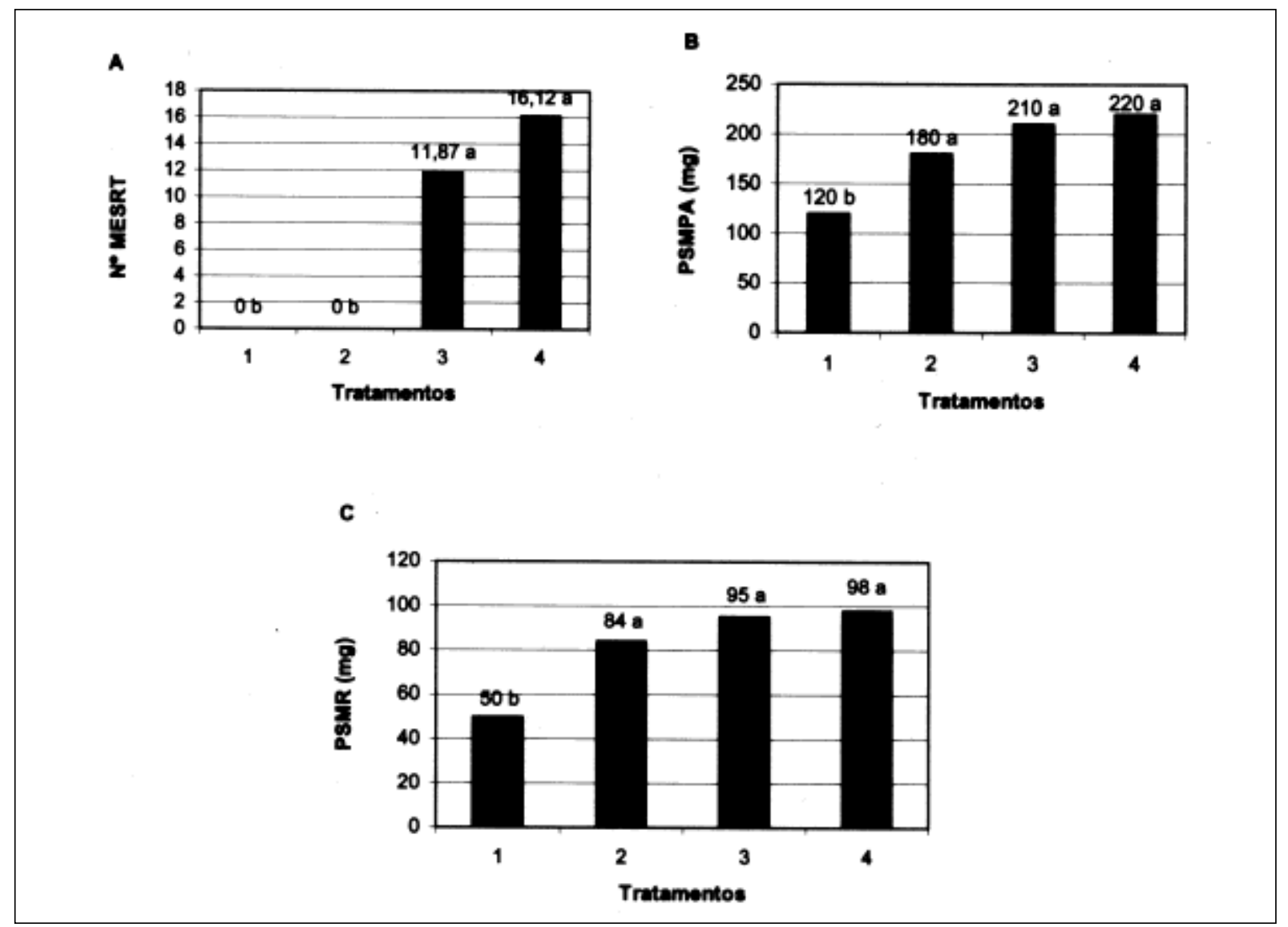

Figura 2 - Relação entre o número médio de estruturas semelhantes a raízes tuberosas ( $\mathrm{N}^{\mathrm{o}} \mathrm{MESRT}$ - (A), peso seco médio da parte aérea (PSMPA) - (B) e o peso seco médio de raízes (PSMR) - (C) e os tratamentos: 1) ausência de filtro amarelo e ausência de reguladores de crescimento; 2) filtro amarelo (FA) + ácido naftaleno acético (ANA)- (4mg L $\left.{ }^{-1}\right)+$ benzilaminopurina (BAP)$\left.\left.\left(2 \mathrm{mg} \mathrm{L}^{-1}\right) ; 3\right) \mathrm{FA}+\mathrm{ANA}\left(0,3 \mathrm{mg} \mathrm{L}^{-1}\right)+\mathrm{BAP}\left(2 \mathrm{mg} \mathrm{L}^{-1}\right) ; 4\right) \mathrm{FA}+\mathrm{ANA}\left(0,3 \mathrm{mg} \mathrm{L}^{-1}\right)+$ cinetina $\left(6 \mathrm{mg} \mathrm{L}^{-1}\right)$. Os valores não seguidos de mesma letra diferem entre si, pelo teste de Scott \& Knott em nível de $5 \%$ de probabilidade de erro.

Ciência Rural, v. 33, n. 3, mai-jun, 2003. 
benzilaminopurina $\left(2 \mathrm{mg} \mathrm{L}^{-1}\right)$. Em contrapartida, no tratamento seis, onde interagiram ácido naftaleno acético $\left(0,3 \mathrm{mg} \mathrm{L}^{-1}\right)$ e benzilaminopurina $\left(2 \mathrm{mg} \mathrm{L}^{-1}\right)$, sem carvão ativado, o peso seco de raízes foi significativamente maior (Figura 3). O carvão ativado em plântulas de mandioca (M. esculenta) in vitro, também inibe o crescimento do sistema radicular, conforme relata FIGUEIREDO (1996).

$\mathrm{Na}$ avaliação do efeito do filtro amarelo, quanto ao peso seco de raízes, os tratamentos mais eficazes foram aqueles que utilizaram filtro amarelo juntamente com ácido naftaleno acético $\left(0,3 \mathrm{mg} \mathrm{L}^{-1}\right) \mathrm{e}$ benzilaminopurina $\left(2 \mathrm{mg} \mathrm{L}^{-1}\right)$; filtro amarelo com ácido naftaleno acético $\left(4 \mathrm{mg} \mathrm{L}^{-1}\right)$ e benzilaminopurina $\left(2 \mathrm{mg} \mathrm{L}^{-1}\right)$; filtro amarelo com ácido naftaleno acético $\left(0,3 \mathrm{mg} \mathrm{L}^{-1}\right)$ e cinetina $\left(6 \mathrm{mg} \mathrm{L}^{-1}\right)$, em que não houve diferença significativa no uso destas combinações. A testemunha (ausência de filtro amarelo e reguladores de crescimento), apresentou o menor resultado para esta variável de avaliação. Plântulas de mandioca ( $\boldsymbol{M}$. esculenta) sob efeito de filtro de luz (amarelo, azul e vermelho), proporcionaram maiores números de raízes na ausência e presença de filtro amarelo em relação aos filtros de cores azul e vermelho (SATO, 1999).

No tocante à interação fotoperíodo/ temperatura, a interação do fotoperíodo de 16 horas de luz com temperatura de $25^{\circ} \mathrm{C}$, proporcionou melhor crescimento do sistema radicular em comparação aos fotoperíodos de 8,10 e 12 horas de luz associado à temperatura de $15^{\circ} \mathrm{C}$ (Figura 3 ). Sob fotoperíodos de 0 , $8,12,16$ e 24 horas de luz associado à temperatura de $25^{\circ} \mathrm{C}$, foi observado que há maior tendência de

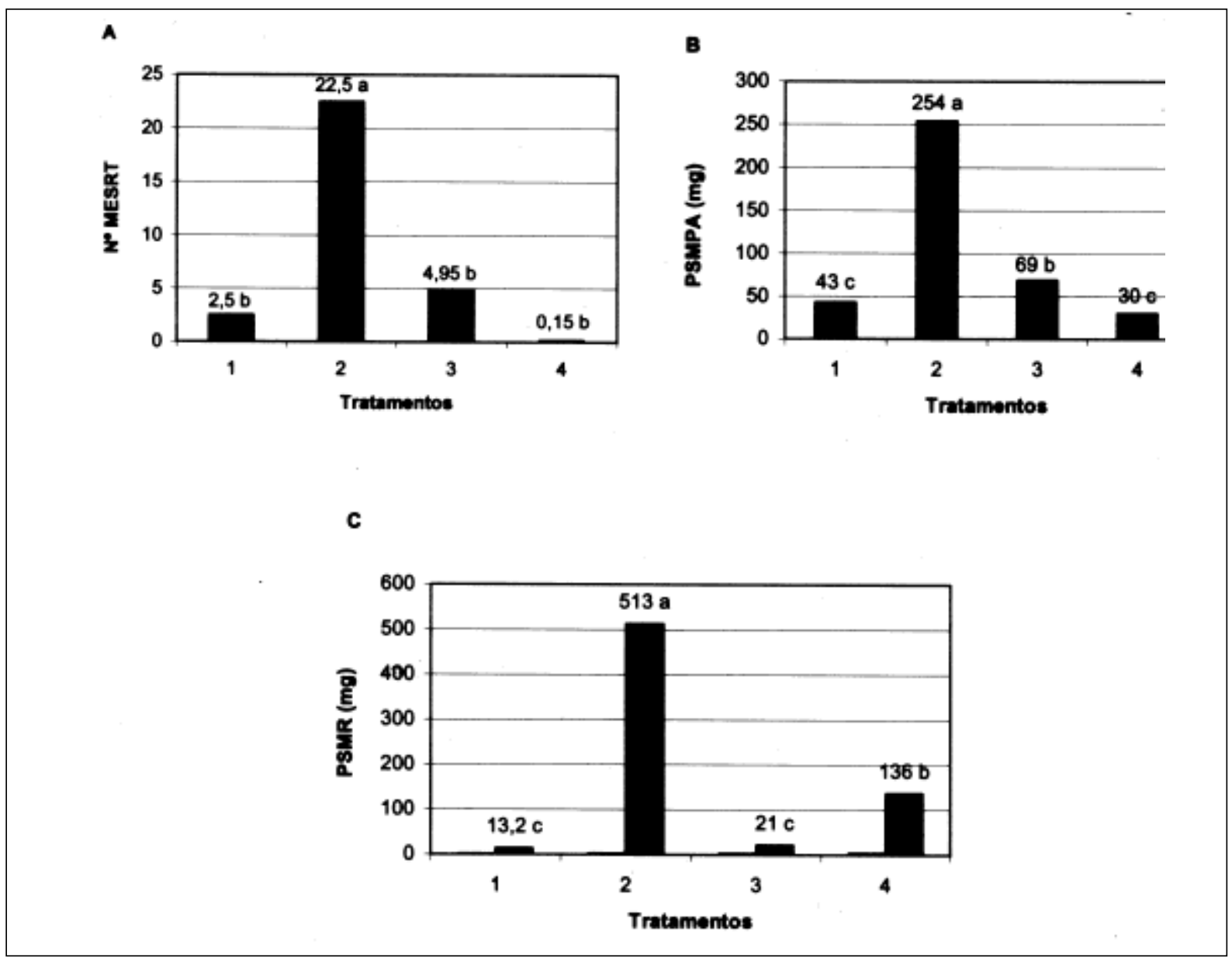

Figura 3 - Relação entre o número médio de estruturas semelhantes a raízes tuberosas ( $\mathrm{N}^{\circ}$ MESRT) - (A), peso seco médio da parte aérea (PSMPA) - (B) e o peso seco médio de raízes (PSMR) - (C) e os tratamentos: 1) 8 horas (h) de luz +16 horas (h) de escuro + ácido naftaleno acético (ANA)- $\left(0,3 \mathrm{mg} \mathrm{L}^{-1}\right)+$ cinetina (CIN)- $\left.\left(6 \mathrm{mg} \mathrm{L}^{-1}\right) ; 2\right) 16 \mathrm{~h} \mathrm{luz}+8 \mathrm{~h}$ escuro + ANA $\left(0,3 \mathrm{mg} \mathrm{L}^{-1}\right)+\mathrm{CIN}(6$

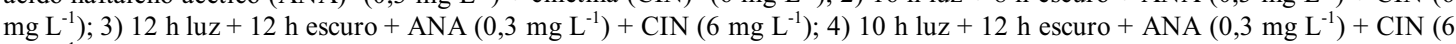
$\left.\mathrm{mg} \mathrm{L}^{-1}\right)$. Os valores não seguidos de mesma letra diferem entre si, pelo teste de Scott \& Knott em nível de 5\% de probabilidade de erro.

Ciência Rural, v. 33, n. 3, mai-jun, 2003. 
produção de matéria seca das raízes à medida que se aumenta o número de horas de exposição à luz (FIGUEIREDO, 1995). Níveis elevados de produção de batata-doce in vivo se atinge implantando a cultura a uma temperatura média ideal de $23,8^{\circ} \mathrm{C}$ ou mais (HENDERSON et al., 1984).

\section{CONCLUSÕES}

A presença de carvão ativado não proporcionou a formação de estruturas semelhantes a raízes tuberosas, no entanto, as raízes formadas na presença do mesmo se apresentaram finas e com redução na matéria seca. Em relação à parte aérea, o carvão ativado inibiu o crescimento da mesma reduzindo o teor de matéria seca.

Na presença de filtro amarelo e reguladores de crescimento nas combinações de benzilaminopurina $\left(2 \mathrm{mg} \mathrm{L}^{-1}\right)+$ ácido naftaleno acético $\left(0,3 \mathrm{mg} \mathrm{L}^{-1}\right)$ e cinetina $\left(6 \mathrm{mg} \mathrm{L}^{-1}\right)+$ ácido naftaleno acético $\left(0,3 \mathrm{mg} \mathrm{L}^{-1}\right)$, houve formação de estruturas semelhantes a raízes tuberosas. No que diz respeito à parte aérea e raiz, a presença de reguladores de crescimento promoveram maiores incrementos de matéria seca.

Em relação à interação fotoperíodo/ temperatura, o fotoperíodo de $16 \mathrm{~h}$ associado à temperatura de $25^{\circ} \mathrm{C}$ proporcionou maior formação de estruturas semelhantes a raízes tuberosas e maiores teores de matéria seca de raízes e parte aérea.

\section{AGRADECIMENTO}

Ao $\mathrm{CNPq}$ pelo apoio financeiro.

\section{REFERÊNCIAS BIBLIOGRÁFICAS}

ECONOMU, A.S.; READ, P.E. Light treatments to improve efficiency of in vitro propagation systems. HortScience, Alexandria, v.22, n.5, p. 751-759, Oct. 1987

FIGUEIREDO, S.A. Influência de reguladores de crescimento e fotoperíodo no crescimento secundário de raízes de Ipomoea batatas (L.) Lam. cv. brazlândia branca em condições in vitro. 1995. 78f. Dissertação (Mestrado em Fisiologia Vegetal) - Curso de Pós-graduação Fisiologia Vegetal, Universidade Federal de Lavras.

FIGUEIREDO, L.F. Indução de raízes tuberiformes de mandioca (Manihot esculenta Crantz) in vitro em hidroponia. 1996. 105f. Dissertação (Mestrado em Fisiologia Vegetal) - Curso de Pós-graduação Fisiologia Vegetal, Universidade Federal de Lavras.
FOLQUER, F. La batata (camote): estudio de la planta y su produccion comercial. San José, Costa Rica : Hemisfério Sul, 1978. 134p.

FRIDBORG, G.; ERIKSSON, T. Effects of activated charcoal on growth and morphogenesis in cell cultures. Physiologia Plantarum, Copenhagen, v.34, n.4, p.306-308, 1975.

HANGARTER, R.P.; STASINOPOULOS, T.C. Effect of Fe catalyzed photooxidation of EDTA on root growth in plant culture media. Plant Physiology, Washington, v.96, p.843-847, 1991.

HENDERSON, J.H.M.; PHILLS, B.R.; WHATLEY, B.T. Sweet Potato. In: SHARP, W.R. et al. Hanbbook of plant cell culture. New York: MacMillan, 1984. V.2. p.302-326.

McDAVID, C.R; ALAMU, S. The effect of growth regulators on tuber initiation and growth in rooted leaves of two sweet potato cultivars. Annals of Botany, London, v.45, n.3, p.363364, 1980 .

MURASHIGE, T; SKOOG, F. A revised medium for rapid growth and biossays with tabacco tissue cultures. Physiology Plantarum, Copenhagen, v.15, n.3, p.473-497, 1962.

PASQUAL, M.; HOFFMANN, A.; RAMOS, J.D. Cultura de tecidos: tecnologia e aplicações - introdução: fundamentos básicos. Lavras-MG : UFLA/FAEPE, 1997. 159p.

ROCA, W.M.; REYES, R.R.; BELTRÁN, J. Effect of various factors on minimal growth in tissue culture storange of cassava germoplasm. In: SYMPOSIUM OF THE INTERNACIONAL SOCIETY FOR TROPICAL ROOT CROPS, 6., 1983, Lima. Proceedings... Lima : CIP, 1984. 630p.

SATO, A.S. Micropropagação e protocolo para transformação de Mandioca (Manihot esculenta crantz) via Agrobacterium rhizogenes. 1999. 90f. Tese (Doutorado em Fitotecnia) - Curso de Pós-graduação em Fitotecnia, Universidade Federal de Viçosa.

SILVA, S. de O.C.; SOUZA, A.S.; PAZ, O.P. Efeito da multiplicação vegetativa in vitro na produtividade de batatadoce (Ipomoea batatas (L.) Lam). Revista Brasileira de Fisiologia Vegetal, São Carlos, v.3, n.1, p.47-52, 1991.

SCOTT, A.J.; KNOTT, M. A cluster analysis method for grouping means in the analysis of variance. Biometrics, Washington, v.30, n.4, p.507-512, 1974.

STASINOPOULOS, T.C.; HANGARTER, R.P. Preventing photochemistry in culture media by long - Pass light filters alters growth of cultured Tissues. Plant Physiology, Washington, v.93, n.4, p.1365-1369, 1990.

TISSERAT, B. Factors involved in the production of plantlets from date palm callus cultures. Euphytica, Wageningen, v.31, n.1, p.201-214, 1982.

WANG, P.; HU, C. In vitro mass tuberization and virus-free seed-potato production in Taiwan. American Potato Journal, Orono, v.59, n.1, p.33-37, 1982. 